\title{
Knowledge citizen's approach to knowledge sharing, rewards and incentive
}

\author{
Melanie Sutton \\ Knowledge Officer \\ The IQ Business Group \\ msutton@iqgroup.net
}

\section{Introduction}

A recent blog raised an interesting question: Does knowledge sharing occur regardless of rewards and incentives because, ultimately, knowledge sharing relies on the motivation and passion from participants who would readily share their experience and knowledge, at the exchange of nothing (tangible)? If yes, this begs yet another question: Are these participants not the 'knowledge citizens' that we have been discussing in this column? If they are, then can endorsing knowledge citizenship not be an answer to the thorny issue of rewards and incentives for knowledge sharing?

\section{Attitude towards knowledge sharing}

Our culture has often offered mixed messages about knowledge sharing and organizations have not always included it in their corporate culture. For years, organizations have rewarded employees who keep information to themselves, that is, a person's value to a corporation is what he or she knows and what others do not.

However, we know that this is an archaic approach and knowledge sharing is regarded as one of the basic requirements to do business on a daily basis. Knowledge sharing should not merely be integrated into a job description but also into the value system of an organization. Hence organizations have begun to implement strategies aimed at changing these outmoded attitudes. These strategies are peppered with a variety of incentives that demonstrate that organizations are serious about sharing knowledge (Stevens 2000).

Today, motivating knowledge sharing must be demonstrated at every level in an organization, that is, from written messages posted above the water cooler to discussions in the boardroom - all must reflect the need to share knowledge. An example of knowledge sharing is demonstrated by an organization that requires its employees to commit to share their knowledge in a formal way at least once a year by contributing an original research paper, providing insight into a new technology or project management technique, or a sample deliverable or report on the lessons learned from a client project. Their biggest challenge has been in encouraging people to write down their insights so that anyone who needs them can retrieve them electronically (Moore 1999).

Sharing is often an explicit requirement built into most performance evaluations to demonstrate how each employee has made a contribution to the collective intellectual capital and participated in knowledge sharing activities such as responding to posted questions on an 
intranet or publishing research.

Knowledge practitioners suggest that education is the key to overcoming knowledge hoarding behaviour. Organizations need to explain and demonstrate to people how it is in their best interest to share knowledge, that is, a person may be more willing to share information if they have reason to expect information from peers in return.

\section{Popular approaches to rewards and incentives}

The rewards and recognition programmes for knowledge sharers range from kudos in the company newsletter to substantial pay bonuses. Having your name on a plaque above the water cooler may not seem much of an incentive but it demonstrates to everyone the characteristics the company values. Many organizations evaluate employees for raises, advancement and extra vacation time depending on how much they participate in knowledge sharing activities (Stevens 2000).

Literature also suggests that incentives must be aimed at different levels in the organization to win over executives, department heads and individuals and encourage them to share their knowledge with their peers (Stevens 2000). In addition, organizations should explicitly identify behaviours that they want to encourage and others they want to eliminate and then incentivize the positive behaviours.

Recognition is important and employees want their organizations to be appreciative of good work. Annual organization awards where peers are involved in the selection of individuals who receive the award for outstanding achievement and not day-to-day work are an effective way in which to incentivize individuals (Sirota 2005).

A Wall of Fame, with plaques showing the names of employees who have excelled at knowledge sharing is also a popular approach to recognize employees who contribute directly to the company's success by sharing or using existing knowledge and demonstrates the company's commitment to sharing knowledge (Stevens 2000).

Many organizations use internal communications to continually motivate the benefits and value of documenting knowledge. They encourage participation through rewards and incentives from invitations to conferences with speakers known in the industry to golf shirts and movie tickets and through public recognition of key contributions in newsletters and flyers (Moore 1999).

Interestingly, the Buckman Laboratories organization, widely recognized as a leader in knowledge management, does not subscribe to incentives or recognition programmes. Instead it tries to encourage knowledge sharing by developing an atmosphere of trust among employees and between the company and the individual, and operates on the maxim that the people one shares the most ideas and thoughts with are those people that you trust. The organization has a code of ethics which states: 'We [treat] each other with dignity and respect, striving to maintain continuous and positive communications ... we will recognise and reward the contributions and accomplishments of each individual' (Stevens 2000).

Knowledge workers want to have some sort of recognition for all the knowledge and resources that they have shared so far. But recognition does not always include cash. There are many ways of recognizing knowledge sharing apart from financial rewards. There will always be a group of people who will share their knowledge and experience even if financial rewards are not in place for the group itself.

Knowledge citizen's approach to sharing, rewards and incentives 
We recognize that 'the people who will be willing to continue sharing their knowledge regardless of reward' are indeed knowledge citizens. As we know, knowledge citizenship starts at an individual level. Those who have the motivation and passion to readily share their experience and knowledge, at the exchange of nothing tangible, but who:

- feel connected to something bigger than their individual knowledge;

- have experienced and benefited from sharing knowledge, to belonging to a group of like minded individuals;

- have a desire to mentor others;

- can build and appreciate trusting relationships;

- want to learn more;

- need to learn more; and

- have an innate curiosity that allows them to trust that by sharing their own knowledge and experience;

gain intangible benefits, of belonging and of learning.

For knowledge citizens, reward is the recognition from their peers or recognition as subject matter experts in their own areas of expertise. Recognition by reputation is something that will have a higher chance of surviving in the current business environment.

Stevens (2000) suggests that organizations should hire people who will share, that is, hire knowledge citizens. If you want employees who share their knowledge, it is best to encourage that from the beginning - hire people with whom your employees feel they want to work and share knowledge.

People willingly share knowledge when they have a common interest. Organizations cannot legislate this from the top down; people must have a passion for the subject. The creation of groups centred on interests is the incentive, within such groups knowledge sharing happens automatically and in unpredictable ways.

Encouraging knowledge citizenship means creating an environment that is conducive for knowledge sharing and learning to take place, for example inter-group knowledge sharing through conferences, classes and mentoring programmes. Establishing communities of knowledge sharing can be expanded to a wider network where people can get to know each other although they might never meet in person (people tend to share knowledge only among the network of people they happen to know).

Knowledge sharing is a cultural issue. How many people do you share an idea with? How many phone calls do you make when trying to track down an answer to a question? When you find the solution to a problem, how often do you look around to find out if someone else might be helped by the answer? Results will indicate the current state of knowledge sharing (Stevens 2000).

Knowledge citizens know what they are really passionate about and they convey this message to colleagues as they come across as excited, energetic and enthusiastic, all of the qualities people like to see in others. If people like you, they are more likely to share knowledge and experience.

The communities of practice and technology infrastructure initiatives have inspired similar activities. For example, the Finance Industry Group in Europe has established expert groups whose members have expertise in related core competencies such as risk management. Their goal is not to only share intellectual capital but also to mentor others to grow their expertise in the discipline. These efforts will grow organically and complement the corporate-wide 
initiatives (Moore 1999).

\section{Conclusion}

Although, organizations cannot expect total commitment from all employees, by encouraging a knowledge citizen approach, an organization is building a sustainable approach to knowledge sharing because it is not only building a programme that may last as long as the current management is in place, but it is building a culture, an attitude, it is building people on an individual level, as citizens. These people will make the world a better place. Rewards will be intrinsic and can be complemented by incentives such as movie tickets, conference opportunities and recognition rewards.

\section{References}

Gallo, C. 26. Starbucks' secret ingredient - how you can incorporate coffee chain chairman Howard Schultz' persuasive communication skills in your

workplace. [Online.] Available WWW:

http://www.businessweek.com/smallbiz/content/may2006/sb20060505_893499.htm? campaign_id=rss_topStories. (Accessed 28 August 2006).

Knowledge Management: Big challenges, big rewards. 1999. CIO Special Advertising Supplement. [Online.] Available WWW http://www.cio.com/sponsors/091599_km_1.html. (Accessed 28 August 2006).

Moore, A. 1999. An environment for innovation: American Management Systems. [Online.] Available at http://www.kmworld.com.

Sirota, D. 2005. Giving employees what they want: the rewards are huge. In: Sirota, D., Mischkind, L.A. and Meltzer, M.I. The enthusiastic employee: how companies profit by giving workers what they want. Wharton School Publishing.

\section{About the author}

Melanie Sutton (BA, Postgraduate Diploma in Information Management) is a Senior Principal Consultant in the Enterprise Content Management Discipline and a member of Intellectual Property Forum at The IQ Business Group, South Africa.

\section{Disclaimer}

Articles published in SAJIM are the opinions of the authors and do not necessarily reflect the opinion of the Editor, Board, Publisher, Webmaster or the Rand Afrikaans University. The user hereby waives any claim he/she/they may have or acquire against the publisher, its suppliers, licensees and sub licensees and indemnifies all said persons from any claims, lawsuits, proceedings, costs, special, incidental, consequential or indirect damages, including damages for loss of profits, loss of business or downtime arising out of or relating to the user's use of the Website. 